\title{
Changes in the Prevalence, Treatment and Control of Hypertension in Germany? A Clinical-Epidemiological Study of 50.000 Primary Care Patients
}

\author{
Alexander Michael Labeit ${ }^{1,2 *}$, Jens Klotsche ${ }^{3}$, Lars Pieper $^{3}$, David Pittrow ${ }^{3}$, Franziska Einsle ${ }^{3}$, Günter \\ Karl Stalla ${ }^{4}$, Hendrik Lehnert ${ }^{5}$, Sigmund Silber ${ }^{6}$, Andreas Michael Zeiher ${ }^{7}$, Winfried März ${ }^{8,9,10}$, \\ Martin Wehling ${ }^{1}$, Hans-Ulrich Wittchen ${ }^{3}$
}

1 Clinical Pharmacology Mannheim, Institute of Experimental and Clinical Pharmacology and Toxicology, Medical Faculty Mannheim of the University of Heidelberg, Heidelberg, Germany, 2 Department of Health Sciences, University of Leicester, Leicester, United Kingdom, 3 Institute of Clinical Psychology and Psychotherapy and Center of Clinical Epidemiology and Longitudinal Studies, TU Dresden, Dresden, Germany, 4 Max Planck Institute of Psychiatry, Munich, Germany, $\mathbf{5}$ Department of Internal Medicine I, University of Lübeck, Lübeck, Germany, 6 Private Cardiology Practice and Clinic, Munich, Germany, 7 Department of Internal Medicine III, Cardiology, GoetheUniversity Frankfurt, Frankfurt, Germany, 8 Synlab Academy, Synlab Services GmbH, Mannheim, Germany, 9 Mannheim Institute of Public Health, Rupertus Carola University of Heidelberg, Medical Faculty Mannheim, Mannheim, Germany, 10 Clinical Institute of Medical and Chemical Laboratory Diagnostics, Medical University of Graz, Graz, Austria

\section{Abstract}

Introduction: Medical societies have developed guidelines for the detection, treatment and control of hypertension (HTN). Our analysis assessed the extent to which such guidelines were implemented in Germany in 2003 and 2001.

Methods: Using standardized clinical diagnostic and treatment appraisal forms, blood pressure levels and patient questionnaires for 55,518 participants from the cross-sectional Targets and Essential Data for Commitment of Treatment (DETECT) study (2003) were analyzed. Physician's diagnosis of hypertension ( $\mathrm{HTN}_{\mathrm{doc}}$ ) was defined as coding hypertension in the clinical appraisal questionnaire. Alternative definitions used were physician's diagnosis or the patient's self-reported diagnosis of hypertension ( $\mathrm{HTN}_{\text {doc,pat }}$ ), physician's or patient's self-reported diagnosis or a BP measurement with a systolic $\mathrm{BP} \geq 140 \mathrm{mmHg}$ and/or a diastolic $\mathrm{BP} \geq 90\left(\mathrm{HTN}_{\text {doc,pat,bp }}\right)$ and diagnosis according to the National Health and Nutrition Examination Survey ( $\mathrm{HTN}_{\text {NHANES }}$ ). The results were compared with the similar German HYDRA study to examine whether changes had occurred in diagnosis, treatment and adequate blood pressure control (BP below 140/90 mmHg) since 2001. Factors associated with pharmacotherapy and control were determined.

Results: The overall prevalence rate for hypertension was $35.5 \%$ according to $\mathrm{HTN}_{\mathrm{doc}}$ and $56.0 \%$ according to NHANES criteria. Among those defined by NHANES criteria, treatment and control rates were $56.0 \%$ and $20.3 \%$ in 2003 , and these rates had improved from $55.3 \%$ and $18.0 \%$ in 2001 . Significant predictors of receiving antihypertensive medication were: increasing age, female sex, obesity, previous myocardial infarction and the prevalence of comorbid conditions such as coronary heart disease (CHD), hyperlipidemia and diabetes mellitus (DM). Significant positive predictors of adequate blood pressure control were CHD and antihypertensive medication. Inadequate control was associated with increasing age, male sex and obesity.

Conclusions: Rates of treated and controlled hypertension according to NHANES criteria in DETECT remained low between 2001 and 2003, although there was some minor improvement.

Citation: Labeit AM, Klotsche J, Pieper L, Pittrow D, Einsle F, et al. (2012) Changes in the Prevalence, Treatment and Control of Hypertension in Germany? A Clinical-Epidemiological Study of 50.000 Primary Care Patients. PLoS ONE 7(12): e52229. doi:10.1371/journal.pone.0052229

Editor: Robert Clarke, University of Oxford, United Kingdom

Received July 5, 2012; Accepted November 13, 2012; Published December 28, 2012

Copyright: (c) 2012 Labeit et al. This is an open-access article distributed under the terms of the Creative Commons Attribution License, which permits unrestricted use, distribution, and reproduction in any medium, provided the original author and source are credited.

Funding: The study was supported by an unrestricted educational grant from Pfizer. The funders had no role in study design, data collection and analysis, decision to publish, or preparation of the manuscript. This does not alter the authors' adherence to all the PLOS ONE policies on sharing data and materials.

Competing Interests: The authors have read the journal's policy and have the following conflicts: Alexander Michael Labeit, Jens Klotsche, Lars Pieper, David Pittrow, Franziska Einsle, Günter Karl Stalla, Hendrik Lehnert, Andreas Michael Zeiher, Hans-Ulrich Wittchen: none. Sigmund Silber: The author served as an advisor or consultant for Abbott Laboratories, Boston Scientific, Medtronic. Martin Wehling: The author was employed by AstraZeneca R\&D, Mölndal, as director of discovery medicine (translational medicine) from 2003-2006, while on sabbatical leave from his professorship at the University of Heidelberg. After return to this position in January 2007, he receives lecturing and consulting fees from Sanofi-Aventis, Novartis, Takeda, Roche, Pfizer, Bristol-Myers, Daichii-Sankyo, Lilly and Novo-Nordisk. This does not alter the authors' adherence to all the PLOS ONE policies on sharing data and materials. Winfried März is affiliated with Synlab Academy, Synlab Services GmbH, Mannheim, Germany, though it has no bearing on this manuscript. This does not alter the authors' adherence to all the PLOS ONE policies on sharing data and materials.

*E-mail: al247@le.ac.uk 


\section{Introduction}

Hypertension (HTN) is a common cause for patient contacts with primary physicians, and there is evidence of suboptimal treatment and inadequate blood pressure control [1]. In Germany the control status of hypertensive patients in the community [2] and in primary care [3] has been repeatedly and consistently found to be lower in comparison with other European countries and the USA [4,5]. Prompted by these data and because of the medical consequences and economic impact of hypertension, considerable national and international activities targeting improved recognition, treatment and control have been initiated $[6,7]$. Against this background, re-examination of the recorded prevalence and control of hypertension is essential to monitor changes that might have occurred as a result of enhanced prevention and treatment activities. Furthermore, a focus on primary care is appropriate, because of the essential role of primary care physicians as gatekeepers for hypertension management in the German health care system [8].

Patients with hypertension alone have an increased risk for cardiovascular morbidity and mortality [9] and hypertensive patients with DM and/or metabolic syndrome as comorbidities have even an increased risk for cardiovascular morbidity and mortality compared to patients with hypertension alone [10,11]. It has been shown by meta-analyses and different large-scale studies that strict control of risk factors including cardiovascular disease, DM, hyperlipidemia and smoking status in patients with hypertension can effectively reduce cardiovascular mortality among patients with hypertension [12]. A meta-analysis showed that type-2 diabetic patients might benefit more from lower blood pressure goals than non-diabetic patients with hypertension [13]. Consequently, national and international medical societies have developed clear recommendations and guidelines for hypertension and risk factor management and respective therapeutic targets [14]. For example, the Seventh Report of the Joint National Commission on Prevention, Detection, Evaluation and Treatment of High blood pressure guidelines (JNC-7) recommend blood pressure targets with systolic blood pressure levels below $140 \mathrm{mmHg}$ and diastolic blood pressure levels below $90 \mathrm{mmHg}$, while for patients with comorbidities the blood pressure (BP) recommendation has been set at $130 / 80 \mathrm{mmHg}$ [12]. In hypertensive patients with $\mathrm{DM}$, tight control of blood pressure is of particular importance and intense non-pharmacological and pharmacological interventions should be implemented to lower blood pressure to below $130 / 80 \mathrm{mmHg}$ [15]. In contrast to the clear recommendations and guidelines of medical scientific societies, there is increasing evidence for a disparity between scientifically grounded treatment targets and the actual implementation of guidelines by physicians in Germany [16].

Our analysis compares the results of the DETECT study with 55,518 participants in 2003 for the estimated prevalence rates using different definitions for diagnosis of hypertension and compares treatment and control rates with the results of the Hypertension and Diabetes Risk Screening and Awareness Study (HYDRA) study [3] with 45,125 participants in 2001 and also comparisons with other German and international studies are made. At the same time the determinants of pharmacotherapy and adequate blood pressure control including among high-risk patients with comorbidities are examined. We used the criteria of the JNG 7 guidelines for the classification of the severity of hypertension: normal $\mathrm{BP}$ for a systolic $\mathrm{BP}<120 \mathrm{mmHg}$ and a diastolic $\mathrm{BP}<80 \mathrm{mmHg}$; prehypertension for a systolic $\mathrm{BP}$ between 120 to $139 \mathrm{mmHg}$ and/or diastolic BP between 80 to $89 \mathrm{mmHg}$; stage 1 hypertension for a systolic BP between 140 and
159 and/or a diastolic BP between 99 and $90 \mathrm{mmHg}$; stage 2 hypertension for a systolic $\mathrm{BP} \geq 160 \mathrm{mmHg}$ and/or a diastolic $\mathrm{BP} \geq 100 \mathrm{mmHg}$. These categories are almost identical to those suggested by the European Society of Hypertension/European Society for Cardiology (ESH/ESG) [12]. If the systolic and diastolic BP would have led to a different categorisation for hypertension the higher category was chosen.

\section{Methods}

DETECT (Diabetes Cardiovascular Risk-Evaluation: Targets and Essential Data for Commitment of Treatment) was initiated to estimate the prevalence and comorbidity patterns of primary care patients and to evaluate new strategies for the prevention and early detection of chronic diseases $[17,18]$. The DETECT study was designed to evaluate the impact of characteristics of the patient and the physician on diagnosis, treatment and control of hypertension. It is a large-scale, cross-sectional study with longitudinal follow-up of a subcohort and nationally representative of primary care situation in Germany [3]. Sampling and data collection for the DETECT study were very similar to the HYDRA study and based on a nationwide sample of physicians with primary care functions (medical practitioners, generalists, general internists). More information about the DETECT study can be found on http://www.detect-studie.de and about the HYDRA study on http://www.hydra-studie.de. HYDRA was a precursor study of DETECT with identical methods of sampling, design and also assessment of hypertension [19]. All patients consulting a practice for whatever reason on $16^{\text {th }}$ or $18^{\text {th }}$ September 2003 were included in the DETECT study. The sampling was based on 1060 regional segments in Germany (according to the criteria of the Institute for Medical Statistics, Frankfurt am Main, Germany), 7053 primary care physicians being randomly selected as a sample from all 64707 physicians who had been working as primary care physicians in Germany in 2003 [3]. Following a pre-study to determine characteristics of physicians and settings, the cross-sectional baseline study in the year 2003 was based on a sample of 55519 unselected adult patients, who were examined in a total of 3188 nationally representative primary care offices $(73 \%$ general practitioners and $27 \%$ internists). Participating patients completed a standardized questionnaire regarding sociodemographic and lifestyle factors. Physicians completed a standardized questionnaire asking for information about known or newly diagnosed medical conditions and an evaluation of the clinical and therapeutic profiles of the patients. Information about prescribed anti-hypertensive medication and results of the current examination (e.g. blood lipid levels, blood pressure measurements according to the JNC 7 report [20]) were also provided by the physician. For the analysis baseline data of the DETECT study for the year 2003 were used. Age groups were defined as follows: 18-29, 30-44, 45-59, 60-74 and 75+ years.

\section{Ethics Statement}

The DETECT study was approved by the ethics committee of the Dresden University of Technology (TU Dresden). Written informed consent was received from all participants.

\section{Diagnostic Conventions}

In order to allow a comparison of the DETECT study specifically with the previous HYDRA study and further related studies in Germany, this paper applies the methods used and described in a previous study for the measurement of prevalence of hypertension [3]. In DETECT, blood pressure measurements 
were taken in the physicians' offices as routine part of the physical examination and were done by indirect cuff sphygmomanometry after a 10-minute of rest in a sitting position according to the international guidelines [20]. In both studies (HYDRA and DETECT) blood pressure was only measured once. Prevalence rates of hypertension were examined using the following definitions which has also used in the HYDRA study as precursor study: a) physician's diagnosis of hypertension as coded in the clinical appraisal questionnaire $\left(\mathrm{HTN}_{\mathrm{doc}}\right)$; b) physician's diagnosis or the patient's self-reported diagnosis of hypertension $\left(\mathrm{HTN}_{\mathrm{doc},-}\right.$ pat); c) physician's or patient's self-reported diagnosis or a BP measurement with a systolic $\mathrm{BP} \geq 140 \mathrm{mmHg}$ and/or a diastolic $\left.\mathrm{BP} \geq 90\left(\mathrm{HTN}_{\text {doc,pat,bp }}\right) ; \mathrm{d}\right)$ diagnosis according to the National Health and Nutrition Examination Survey (HTN NHANES $_{\text {[ }}$ [21], i.e. a measured $\mathrm{BP} \geq 140 / 90 \mathrm{mmHg}$ or treatment with antihypertensive drugs, irrespective of the doctor's or patient's self-reported diagnosis. For the estimation of the proportion of diagnosed patients $(<140 / 90 \mathrm{mmHg})$ we used the $\mathrm{HTN}_{\text {NHANES }}$ criterion for defining hypertension [21,22]. These patients were defined as treated if they received antihypertensive drugs and the following drug classes were included: ACE inhibitors, AT1-antagonists, beta-blockers, calcium channel blockers and diuretics. These patients were defined as controlled if blood pressure was below 140/90 mmHg.

\section{Cardiovascular Comorbidity}

The physicians' questionnaire explicitly asked for the existence of 28 specified medical diagnoses and also allowed for adding further diagnoses. CHD, DM and hyperlipidemia were exclusively defined as physicians' based diagnoses (newly diagnosed or previously known) [18]. The physicians' questionnaire contained information about previous myocardial infarction and family history of myocardial infarction.

\section{Cardiovascular Risk Factors}

The patients' questionnaire contained information about physical activity and smoking status as cardiovascular risk factors. Physical activity was classified as either more than or equal to 2 hours per week versus physical activity with less than 2 hours per week on average (e.g. gardening, cycling, walking or other sports). Smoking status of the participants was defined as use of any tobacco product in the past 4 weeks and categorized as yes/no. BMI was categorized into three groups: $<25 \mathrm{~kg} / \mathrm{m}^{2}$ (normal), 25 to $<30 \mathrm{~kg} / \mathrm{m}^{2}$ (overweight) and $\geq 30 \mathrm{~kg} / \mathrm{m}^{2}$ (obesity). Waist circumference (WC) was categorized into the following groups: $\leq 94 \mathrm{~cm}$ for males and $\leq 80 \mathrm{~cm}$ for females as not overweight, $>94 \mathrm{~cm}$ and $\leq 102 \mathrm{~cm}$ for males and $>80 \mathrm{~cm}$ and $\leq 88 \mathrm{~cm}$ for females as pre-obese, $>102 \mathrm{~cm}$ for males and $88 \mathrm{~cm}$ for females as obese.

\section{Statistical Analyses}

DETECT study participants were analyzed with respect to socio-demographic, comorbidities and cardiovascular lifestyle risk factors. Gender and age-group specific estimates of prevalence rates of hypertension were determined applying alternative definitions of hypertension in unselected primary care patients. Also the prevalence of hypertension according to JNC 7 categories was analyzed. Determinants associated with pharmacotherapy and adequate BP control of hypertension such as socio-demographic comorbidities and cardiovascular lifestyle risk factors were evaluated using multiple logistic regression. Education in years was included in the models as potentially explanatory factor. The patients were clustered by primary care units and to account for the clustered structure of the data, robust standard errors were estimated by the Huber-White Matrix. Data were weighted for non-response and attrition during the recruitment phase. Categorical data were presented as absolute frequencies (n) and weighted percentages $(\% \mathrm{w})$, metric variables by weighted mean and standard deviation. A two-sided alpha-level of 0.05 was chosen as criterion for statistical significance. All statistical analyses were conducted using STATA 11.2 (Stat Corp. 2009, College Station, Texas, USA).

\section{Results}

Table 1 presents descriptive statistics for sociodemographic and baseline variables for the 55,518 participants of the DETECT study in 2003. The average systolic BP was $131.7 \mathrm{mmHg}$ and diastolic BP was $79.9 \mathrm{mmHg}$. Of the participants of the DETECT study, $12.1 \%$ had physician diagnosed DM, 29.5\% hyperlipidemia, $14.7 \%$ CHD and $4.2 \%$ previous myocardial infarction. Physician based diagnosis of hypertension $\left(\mathrm{HTN}_{\mathrm{doc}}\right)$ was present in $35.5 \%$ of all participants (see table 2). The prevalence rate of physician diagnosed hypertension increased from the youngest age group (18 to 29 years) to the oldest one ( 75 years and above) from $2.9 \%$ from to $62.6 \%$. Physician's diagnosis or the patient's selfreported diagnosis of hypertension $\left(\mathrm{HTN}_{\text {doc,pat }}\right)$ showed slightly higher prevalence rates: $41.8 \%$ in all participants, $6.4 \%$ in the youngest age group and $69.5 \%$ in the oldest age group. Physician's or patient's self-reported diagnosis or a BP measurement with a systolic $\mathrm{BP} \geq 140 \mathrm{mmHg}$ and/or a diastolic $\mathrm{BP} \geq 90\left(\mathrm{HTN}_{\text {doc,pat,bp }}\right)$ prevalence rates increased to $55.2 \%$ in all participants and were $15.4 \%$ and $82.1 \%$ in the youngest and oldest age group, respectively. Prevalence rates for hypertension diagnosis according to the National Health and Nutrition Examination Survey ( $\left.\mathrm{HTN}_{\text {NHANES}}\right)$ were in a similar range as for $\mathrm{HTN}_{\text {doc,pat,bp: }}$ : $56.0 \%$ in all participants, $13.3 \%$ in the youngest and $86.8 \%$ in the oldest age group. Comparing the estimated prevalence rates for $\mathrm{HTN}_{\text {doc }}, \mathrm{HTN}_{\text {doc,pat }}, \mathrm{HTN}_{\text {doc,pat,bp }}$ and $\mathrm{HTN}_{\text {NHANES, the largest }}$ differences measured as ratio of 2 estimated prevalence rates were seen in the youngest age group comparing $\mathrm{HTN}_{\mathrm{doc}}$ and $\mathrm{HTN}_{\text {NHANES. The biggest percent difference in absolute number }}$ was present in the oldest age group comparing $\mathrm{HTN}_{\mathrm{doc}}$ to

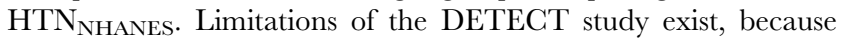
there was only single measurement of blood pressure in a primary care setting done. Some patients have been excluded from the study, because of time restrictions of the physician or no clinical assessment was possible [23]. Several measurements are recommended and prevalence of hypertension is dependent from the setting and inclusion criteria of patients [18].

The categories of the measured BP values according to the JNC 7 classification are shown in table 3 stratified by age and sex. $14.9 \%$ of the participants had normal blood pressure, $44.6 \%$ prehypertension, $28.8 \%$ stage 1 hypertension and $11.6 \%$ stage 2 hypertension. The prevalence rates of hypertension stages 1 and 2 increased together with age. In participants between age 18 and 29 prevalence rates were $10.2 \%$ and $1.8 \%$, in patients above 75 years of age prevalence rates were $41.2 \%$ and $18.7 \%$, respectively. The mean systolic BP increased continuously with age up to $140.6 \mathrm{mmHg}$ in participants above 75 years of age and diastolic BP increased up to $81.6 \mathrm{mmHg}$ in the age group 60-74 years, but decreased to $79.9 \mathrm{mmHg}$ again in the oldest age group.

\section{Diagnosis, Treatment and Control Rates in the DETECT Study}

Across all age groups $61.5 \%$ of $\mathrm{HTN}_{\text {NHANES }}$ cases were diagnosed (coded in the clinical appraisal) by the physicians. In the youngest there was the smallest proportion of diagnosed 
Table 1. Sample characteristics of DETECT study participants.

\begin{tabular}{|c|c|c|c|c|c|c|}
\hline & \multicolumn{2}{|l|}{ Total } & \multicolumn{2}{|l|}{ Male } & \multicolumn{2}{|c|}{ Female } \\
\hline & \multicolumn{2}{|c|}{$(\mathrm{N}=55,518)$} & \multicolumn{2}{|c|}{$(\mathrm{N}=22,679)$} & \multicolumn{2}{|c|}{$(\mathrm{N}=32,839)$} \\
\hline & $\mathbf{N}$ & $\% w$ & $\mathbf{N}$ & $\% w$ & $\mathbf{N}$ & $\% w$ \\
\hline Age (mean/sd) & \multicolumn{2}{|l|}{$53.8 / 17.4$} & \multicolumn{2}{|c|}{$54.5 / 16.8$} & \multicolumn{2}{|c|}{$53.3 / 17.8$} \\
\hline $18-29$ years & 6,031 & 11 & 2,249 & 9.9 & 3,782 & 11.7 \\
\hline 30-44 years & 11,525 & 21 & 4,328 & 19.5 & 7,197 & 22.1 \\
\hline $45-59$ years & 13,555 & 24.3 & 5,599 & 24.5 & 7,956 & 24.1 \\
\hline 60-74 years & 17,934 & 31.9 & 8,087 & 35.3 & 9,847 & 29.5 \\
\hline $75+$ years & 6,473 & 11.9 & 2,416 & 10.9 & 4,057 & 12.6 \\
\hline Systolic blood pressure, (mean/sd) & \multicolumn{2}{|c|}{ 131.7/18.4 } & \multicolumn{2}{|c|}{$133.8 / 17.3$} & \multicolumn{2}{|c|}{$130.3 / 19.0$} \\
\hline Diastolic blood pressure, (mean/sd) & \multicolumn{2}{|l|}{ 79.9/9.9 } & \multicolumn{2}{|c|}{$80.8 / 9.8$} & \multicolumn{2}{|c|}{$79.2 / 10.0$} \\
\hline Years of schooling, (mean/sd) & \multicolumn{2}{|l|}{$10.1 / 2.1$} & \multicolumn{2}{|c|}{$10.2 / 2.2$} & \multicolumn{2}{|l|}{$10.0 / 2.0$} \\
\hline BMI (mean/sd) & \multicolumn{2}{|l|}{$26.8 / 5.3$} & \multicolumn{2}{|l|}{ 27.3/4.7 } & \multicolumn{2}{|c|}{$26.5 / 5.6$} \\
\hline$<25 \mathrm{~kg} / \mathrm{m}^{2}$ & 21,520 & 40.2 & 7,037 & 32.1 & 14,483 & 45.8 \\
\hline $25-29.9 \mathrm{~kg} / \mathrm{m}^{2}$ & 20,383 & 37.3 & 10,201 & 45.8 & 10,182 & 31.5 \\
\hline $30+\mathrm{kg} / \mathrm{m}^{2}$ & 12,491 & 22.5 & 4,986 & 22.2 & 7,505 & 22.7 \\
\hline WC (mean/sd) & \multicolumn{2}{|l|}{$93.8 / 15.6$} & \multicolumn{2}{|c|}{$99.8 / 13.8$} & \multicolumn{2}{|c|}{$89.7 / 15.4$} \\
\hline$\leq 94 \mathrm{~cm}$ (male) $\leq 80 \mathrm{~cm}$ (female) & 15,595 & 31.9 & 6,667 & 33.6 & 8,928 & 30.7 \\
\hline$>94 \mathrm{~cm}-\leq 102 \mathrm{~cm}$ (male) $>80 \mathrm{~cm}-\leq 88 \mathrm{~cm}$ (female) & 10,729 & 21.9 & 5,245 & 26.4 & 5,484 & 18.9 \\
\hline$>102 \mathrm{~cm}$ (male) >88 cm (female) & 22,593 & 46.2 & 7,930 & 40 & 14,663 & 50.4 \\
\hline Current smoker & 13,504 & 26.1 & 6,186 & 29.2 & 7,318 & 24 \\
\hline Physical activity $<2$ hours/week & 16,265 & 34.3 & 5,902 & 30.3 & 10,363 & 37.2 \\
\hline \multicolumn{7}{|l|}{ Comorbidities } \\
\hline CHD & 8,465 & 14.7 & 4,127 & 17.6 & 4,338 & 12.8 \\
\hline Hyperlipidemia & 16,178 & 29.5 & 7,311 & 32.4 & 8,867 & 27.5 \\
\hline Diabetes mellitus & 6,895 & 12.1 & 3,969 & 17.2 & 2,926 & 8.6 \\
\hline Myocardial infarction & 2,326 & 4.2 & 1,649 & 7.3 & 677 & 2.1 \\
\hline
\end{tabular}

$\mathrm{N}=55,518, \% \mathrm{w}=$ weighted percentages; $\mathrm{BMI}=$ body mass index in $\mathrm{kg} / \mathrm{m} 2$.

Number of valid observations: Blood pressure $n=53,337$ (96.1\%); Years of schooling $n=53,406$ (96.2\%); Body mass index.

$n=54,393$ (98.0\%); Waist circumference $n=48,918$ (88.1\%); Smoking status $n=52,589$ (94.7\%); Physical activity $n=48,249(86.9 \%)$

doi:10.1371/journal.pone.0052229.t001

HTN $_{\text {NHANES }}$ cases (17.4\% only). In the age group $75+$ the fraction of physician diagnosed cases was highest $(71.0 \%)$. The rates of $\mathrm{HTN}_{\text {NHANES }}$ cases, which were diagnosed and also treated by physicians increased with higher age: $12.1 \%$ in the youngest age group and $65.7 \%$ in the oldest age group. Among $\mathrm{HTN}_{\text {NHANES }}$ cases the proportion of patients with adequate blood pressure control was $21.4 \%$ across all groups; it was $5.8 \%$ in the youngest and $23.3 \%$ in the oldest age group.

\section{Comparison between HYDRA and DETECT Study}

The comparison presented in figure 1 reveals that the proportion of diagnosed patients was lower in the DETECT study in comparison to the HYDRA study. These changes are consistent, and are significant $(\mathrm{p}<0.05)$ in all age groups above age 30 for men and women. The comparison between these studies shows also indications of, albeit small, improvements in rates of treated and controlled hypertension. The changes are consistent, although not significant in all gender and age group comparisons. Significant improvements $(\mathrm{p}<0.05)$ in the rates of treatment were found in females 30-44 years of age and in males 30-44 and 4559 years of age. Rates of antihypertensive drug therapy decreased significantly in male patients aged 75 years and older. Adequate
BP control was significantly more common in older female patients (age group 60+ years).

\section{Factors Associated with Pharmacotherapy}

Table 4 shows factors associated with pharmacotherapy for hypertension. Patients in the oldest age group were approximately tenfold more likely to take antihypertensive drugs (OR 10.58, 95\%-CI 8.36-13.39). Further factors associated with receiving antihypertensive medication in NHANES based cases were female sex (OR 1.18, 95\%-CI 1.10-1.27), BMI above $30 \mathrm{~kg} / \mathrm{m}^{2}$ (OR 1.72, 95\%-CI 1.57-1.89), a history of CHD (OR 4.64, 95\%-CI 3.92-5.50), a physician based diagnosis of hyperlipidemia (OR 1.66, 95\%-CI 1.54-1.79), DM (OR 1.98, 95\%-CI 1.79-2.19) or previous myocardial infarction (OR 2.27, 95\%-CI 1.60-3.21). An alternative specification with waist circumference (reference category: not overweight) instead of BMI as a measure of cardiovascular risk gave very similar results. Smoking was negatively associated with receiving antihypertensive medication (OR 0.79, 95\%-CI 0.72-0.86). 
Table 2. Prevalence rates of hypertension by age, sex and type of diagnosis.

\begin{tabular}{|c|c|c|c|c|c|c|c|c|c|c|c|c|c|}
\hline & & \multirow{2}{*}{$\begin{array}{l}\text { no } \\
\text { HTN } \\
\text { doc }\end{array}$} & \multicolumn{2}{|l|}{$\mathrm{HTN}_{\text {doc }}$} & \multirow{2}{*}{$\begin{array}{l}\text { no } \\
\text { HTN }_{\text {doc/Pat }}\end{array}$} & \multicolumn{2}{|c|}{$\mathrm{HTN}_{\text {doc/Pat }}$} & \multirow{2}{*}{$\begin{array}{l}\text { no } \\
\text { HTN }_{\text {doc/Pat/bp }} \\
N\end{array}$} & \multicolumn{2}{|c|}{$\mathrm{HTN}_{\text {doc/Pat/bp }}$} & \multirow{2}{*}{$\begin{array}{l}\text { no } \\
\text { HTN }_{\text {NNANES }}{ }^{\dagger}\end{array}$} & \multicolumn{2}{|c|}{ HTN $_{\text {NHANES }}{ }^{\dagger}$} \\
\hline & & & $\mathbf{N}$ & $\% w$ & & $\mathbf{N}$ & $\% w$ & & $\mathbf{N}$ & $\% w$ & & $\mathbf{N}$ & $\% w$ \\
\hline \multirow[t]{3}{*}{ Total } & Total & 35,354 & 20,164 & 35.5 & 31,858 & 23,660 & 41.8 & 24,569 & 30,949 & 55.2 & 23,148 & 30,189 & 56.0 \\
\hline & Female & 21,539 & 11,300 & 33.6 & 19,667 & 13,172 & 39.3 & 15,701 & 17,138 & 51.6 & 14,969 & 16,620 & 52.0 \\
\hline & Male & 13,815 & 8,864 & 38.3 & 12,191 & 10,488 & 45.5 & 8,868 & 13,811 & 60.4 & 8,179 & 13,569 & 61.9 \\
\hline \multirow{3}{*}{$\begin{array}{l}18-29 \\
\text { years }\end{array}$} & Total & 5,854 & 177 & 2.9 & 5,634 & 397 & 6.4 & 5,099 & 932 & 15.4 & 5,017 & 771 & 13.3 \\
\hline & Female & 3,693 & 89 & 2.3 & 3,586 & 196 & 5.0 & 3,324 & 458 & 12.2 & 3,258 & 372 & 10.3 \\
\hline & Male & 2,161 & 88 & 4.0 & 2,048 & 201 & 8.8 & 1,775 & 474 & 20.8 & 1,759 & 399 & 18.3 \\
\hline \multirow{3}{*}{$\begin{array}{l}30-44 \\
\text { years }\end{array}$} & Total & 10,291 & 1,234 & 10.1 & 9,726 & 1,799 & 14.9 & 8,192 & 3,333 & 28.3 & 8,014 & 3,056 & 27.1 \\
\hline & Female & 6,551 & 646 & 8.5 & 6,250 & 947 & 12.6 & 5,499 & 1,698 & 23.1 & 5,369 & 1,558 & 22.1 \\
\hline & Male & 3,740 & 588 & 12.7 & 3,476 & 852 & 18.8 & 2,693 & 1,635 & 37.0 & 2,645 & 1,498 & 35.5 \\
\hline \multirow{3}{*}{$\begin{array}{l}45-59 \\
\text { years }\end{array}$} & Total & 9,068 & 4,487 & 32.0 & 8,113 & 5,442 & 39.1 & 5,992 & 7,563 & 55.1 & 5,744 & 7,291 & 55.1 \\
\hline & Female & 5,559 & 2,397 & 29.0 & 5,062 & 2,894 & 35.3 & 3,891 & 4,065 & 50.3 & 3,754 & 3,908 & 50.2 \\
\hline & Male & 3,509 & 2,090 & 36.3 & 3,051 & 2,548 & 44.5 & 2,101 & 3,498 & 61.8 & 1,990 & 3,383 & 62.2 \\
\hline \multirow{3}{*}{$\begin{array}{l}60-74 \\
\text { years }\end{array}$} & Total & 7,778 & 10,156 & 56.0 & 6,460 & 11,474 & 63.5 & 4,149 & 13,785 & 76.7 & 3,569 & 13,664 & 79.0 \\
\hline & Female & 4,294 & 5,553 & 55.7 & 3,590 & 6,257 & 63.0 & 2,321 & 7,526 & 76.2 & 2,104 & 7,375 & 77.5 \\
\hline & Male & 3,484 & 4,603 & 56.2 & 2,870 & 5,217 & 64.0 & 1,828 & 6,259 & 77.3 & 1,465 & 6,289 & 80.9 \\
\hline \multirow{3}{*}{$\begin{array}{l}\geq 75 \\
\text { years }\end{array}$} & Total & 2,363 & 4,110 & 62.6 & 1,925 & 4,548 & 69.5 & 1,137 & 5,336 & 82.1 & 804 & 5,407 & 86.8 \\
\hline & Female & 1,442 & 2,615 & 63.3 & 1,179 & 2,878 & 70.0 & 666 & 3,391 & 83.1 & 484 & 3,407 & 87.1 \\
\hline & Male & 921 & 1,495 & 61.2 & 746 & 1,670 & 68.8 & 471 & 1,945 & 80.5 & 320 & 2,000 & 86.1 \\
\hline
\end{tabular}

$\mathrm{N}=55,518, \uparrow \mathrm{N}=53,337$ patients with valid blood pressure assessment; \% $=$ weighted percentages HTNdoc: doctor's diagnosis; HTNdoc/pat: doctor's or patient's diagnosis; HTNdoc/pat/bp: doctor's or patient's diagnosis or blood pressure 140/90 mmHg; HTNHANES: blood pressure $>140 / 90 \mathrm{mmHg}$ or receiving antihypertensive therapy. doi:10.1371/journal.pone.0052229.t002

Table 3. Prevalence of JNC 7 Blood Pressure Categories.

\begin{tabular}{|c|c|c|c|c|c|c|c|c|c|}
\hline & & \multicolumn{2}{|c|}{$B P<120 / 80 \mathrm{mmHg}$} & \multicolumn{2}{|c|}{ BP $120-139 / 80-89 \mathrm{mmHg}$} & \multicolumn{2}{|c|}{ BP $140-159 / 90-99 \mathrm{mmHg}$} & \multicolumn{2}{|c|}{$B P \geq 160 / 100 \mathrm{mmHg}$} \\
\hline & & $\mathbf{N}$ & $\% w$ & $\mathbf{N}$ & $\% w$ & $\mathbf{N}$ & $\% w$ & $\mathbf{N}$ & $\% w$ \\
\hline \multirow[t]{3}{*}{ Total $\dagger$} & Total & 7,839 & 14.9 & 23,890 & 44.6 & 15,489 & 28.8 & 6,119 & 11.6 \\
\hline & Female & 5,729 & 18.5 & 13,894 & 43.8 & 8,486 & 26.6 & 3,480 & 11.2 \\
\hline & Male & 2,110 & 9.8 & 9,996 & 45.8 & 7,003 & 32.1 & 2,639 & 12.3 \\
\hline \multirow[t]{3}{*}{$18-29$ years } & Total & 2,114 & 36.8 & 2,982 & 51.3 & 584 & 10.2 & 108 & 1.8 \\
\hline & Female & 1,608 & 44.7 & 1,699 & 46.2 & 284 & 8.0 & 39 & 1.0 \\
\hline & Male & 506 & 23.1 & 1,283 & 59.9 & 300 & 13.8 & 69 & 3.2 \\
\hline \multirow[t]{3}{*}{$30-44$ years } & Total & 2,681 & 24.6 & 5,882 & 52.9 & 1,935 & 17.3 & 572 & 5.2 \\
\hline & Female & 2,155 & 31.5 & 3,539 & 50.9 & 975 & 13.9 & 258 & 3.7 \\
\hline & Male & 526 & 13.1 & 2,343 & 56.3 & 960 & 22.9 & 314 & 7.7 \\
\hline \multirow[t]{3}{*}{$45-59$ years } & Total & 1,630 & 12.8 & 6,089 & 46.6 & 3,880 & 29.5 & 1,436 & 11.1 \\
\hline & Female & 1,216 & 16.2 & 3,623 & 47.2 & 2,091 & 27.0 & 732 & 9.6 \\
\hline & Male & 414 & 7.9 & 2,466 & 45.9 & 1,789 & 33.0 & 704 & 13.2 \\
\hline \multirow[t]{3}{*}{$60-74$ years } & Total & 1,081 & 6.3 & 6,768 & 39.1 & 6,519 & 37.7 & 2,865 & 17.0 \\
\hline & Female & 583 & 6.2 & 3,723 & 39.2 & 3,518 & 36.8 & 1,655 & 17.8 \\
\hline & Male & 498 & 6.5 & 3,045 & 38.9 & 3,001 & 38.8 & 1,210 & 15.9 \\
\hline \multirow[t]{3}{*}{$\geq 75$ years } & Total & 333 & 5.4 & 2,169 & 34.8 & 2,571 & 41.2 & 1,138 & 18.7 \\
\hline & Female & 167 & 4.3 & 1,310 & 33.6 & 1,618 & 41.1 & 796 & 21.0 \\
\hline & Male & 166 & 7.2 & 859 & 36.7 & 953 & 41.3 & 342 & 14.8 \\
\hline
\end{tabular}

${ }^{\dagger} \mathrm{N}=53,337$ patients with valid blood pressure assessment; \%w = weighted percentages; $\mathrm{BP}=$ blood pressure.

doi:10.1371/journal.pone.0052229.t003 

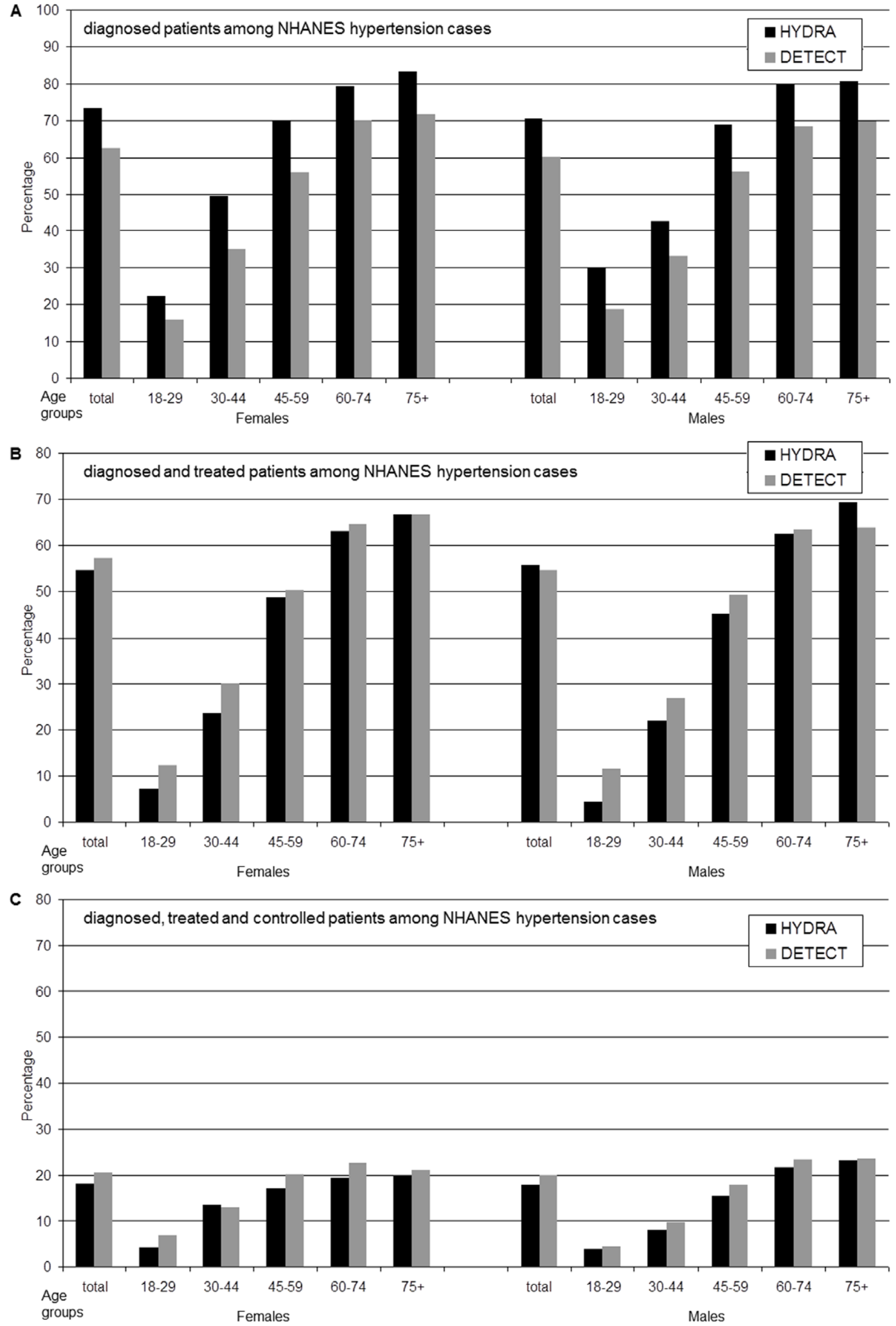
Figure 1. Diagnosis, treatment and control rates among NHANES hypertension cases in DETECT and HYDRA study. Comparison between DETECT study $(\mathrm{N}=30189)$ and HYDRA study $(\mathrm{N}=22744)$ for diagnosis, treatment and control rates. Diagnosed = diagnosed by physician among NHANES cases; diagnosed+treated=diagnosed by physician and treated by antihypertensive drugs among NHANES cases; diagnosed+treated+controlled = diagnosed by physician, treated by antihypertensive drugs and blood pressure $<140 / 90 \mathrm{mmHg}$ among NHANES cases. A comparison between both studies reveals that the proportion of diagnosed patients among NHANES hypertension cases was lower in the first study for all age groups above age 30 for men and women $(p<0.05)$. Small (significant) improvements in rates of diagnosed and treated hypertension were found in females 30-44 years of age and in males $30-44$ and $45-59$ years of age ( $<<0.05)$. Small (significant) improvements in rates of diagnosed, treated and controlled hypertension were found in females 60-64 years of age and in males 30-44 and 45-59 years of age $(p<0.05)$.

doi:10.1371/journal.pone.0052229.g001

\section{Factors Associated with Blood Pressure Control}

In $\mathrm{HTN}_{\mathrm{doc}}$ cases, the factors associated with adequate blood pressure control (less than 140/90 $\mathrm{mmHg}$ ) were female sex (OR $1.16,95 \%$-CI 1.07-1.25), the presence of CHD (OR 1.25, 95\%CI 1.13-1.39), previous myocardial infarction (OR 1.76, 95\%-CI 1.50-2.05) and antihypertensive medication (OR 1.41, 95\%-CI 1.23-1.61) (table 5). With increasing age the likelihood of adequate blood pressure control was reduced (OR 0.57, 95\%-CI 0.39-0.82 for the highest age group) and also for a BMI above $30 \mathrm{~kg} / \mathrm{m}^{2}$
(OR 0.67, 95\%-CI 0.61-0.74). An alternative specification with waist circumference (reference category: not overweight) instead of BMI as a measure of cardiovascular risk gave also very similar results in this regression. Comorbidities (hyperlipidemia, DM and lifestyle factors) such as physical activity and smoking status) had no effect on blood pressure control.

Table 4. Determinants of pharmacotherapy among NHANES hypertension cases.

\begin{tabular}{|c|c|c|c|c|c|c|c|}
\hline & \multirow{3}{*}{$\frac{\text { All }}{\mathbf{N}}$} & \multicolumn{6}{|c|}{ Antihypertensive treatment $(\mathrm{N}=21,323)$} \\
\hline & & \multicolumn{2}{|c|}{ With treatment } & \multicolumn{2}{|c|}{ Unadjusted } & \multicolumn{2}{|c|}{ Adjusted $^{\dagger}$} \\
\hline & & $\mathbf{N}$ & $\% w$ & $\mathbf{O R}^{\#}$ & $95 \% \mathrm{Cl}$ & $\mathbf{O R}^{\dagger}$ & $95 \% \mathrm{Cl}$ \\
\hline Male gender & 12,941 & 9,464 & 72.3 & \multicolumn{2}{|c|}{ (reference) } & \multicolumn{2}{|c|}{ (reference) } \\
\hline Female gender & 15,876 & 11,859 & 73.9 & $1.08^{*}$ & $1.02-1.14$ & $1.18^{*}$ & $1.10-1.27$ \\
\hline \multicolumn{8}{|l|}{ Age in years } \\
\hline $18-29$ & 682 & 146 & 20 & \multicolumn{2}{|c|}{ (reference) } & \multicolumn{2}{|c|}{ (reference) } \\
\hline 30-44 & 2,811 & 1,194 & 40.8 & $2.75^{*}$ & $2.24-3.39$ & $2.08^{*}$ & $1.67-2.59$ \\
\hline $45-59$ & 6,903 & 4,604 & 65.6 & $7.62^{*}$ & $6.24-9.30$ & $4.57^{*}$ & $3.70-5.65$ \\
\hline 60-74 & 13,202 & 10,827 & 81.4 & $17.57^{*}$ & $14.42-21.40$ & $8.19^{*}$ & $6.61-10.16$ \\
\hline$\geq 75$ & 5,219 & 4,552 & 86.5 & $25.68^{*}$ & $20.81-31.68$ & $10.58^{*}$ & $8.36-13.39$ \\
\hline Years of schooling, (mean/sd) & & $9.4 / 2.0$ & & $0.87^{*}$ & $0.86-0.88$ & 0.98 & $0.97-1.00$ \\
\hline \multicolumn{8}{|l|}{$B M I$} \\
\hline$<25 \mathrm{~kg} / \mathrm{m}^{2}$ & 7,095 & 4,745 & 66.3 & \multicolumn{2}{|c|}{ (reference) } & \multicolumn{2}{|c|}{ (reference) } \\
\hline $25-29.9 \mathrm{~kg} / \mathrm{m}^{2}$ & 12,169 & 9,008 & 73.4 & $1.41^{*}$ & $1.32-1.51$ & $1.24^{*}$ & $1.14-1.35$ \\
\hline $30+\mathrm{kg} / \mathrm{m}^{2}$ & 9,186 & 7,283 & 78.2 & $1.82^{*}$ & $1.69-1.96$ & $1.72^{*}$ & $1.57-1.89$ \\
\hline Current non-smoker & 22,809 & 17,536 & 76.1 & \multicolumn{2}{|c|}{ (reference) } & \multicolumn{2}{|c|}{ (reference) } \\
\hline Current smoker & 4,912 & 2,952 & 59.6 & $0.46^{*}$ & $0.43-0.50$ & $0.79^{*}$ & $0.72-0.86$ \\
\hline Physical activity $\geq 2$ hours/week & 16,422 & 12,025 & 72.2 & \multicolumn{2}{|c|}{ (reference) } & \multicolumn{2}{|c|}{ (reference) } \\
\hline Physical activity $<2$ hours/week & 7,903 & 5,660 & 70.9 & $0.94^{*}$ & $0.88-1.00$ & 1.02 & $0.94-1.09$ \\
\hline \multicolumn{8}{|l|}{ Comorbidities } \\
\hline no CHD & 22,829 & 15,639 & 67.6 & \multicolumn{2}{|c|}{ (reference) } & \multicolumn{2}{|c|}{ (reference) } \\
\hline CHD & 5,988 & 5,684 & 94.9 & $8.83^{*}$ & $7.80-9.99$ & $4.64^{*}$ & $3.92-5.50$ \\
\hline no Hyperlipidemia & 16,825 & 11,274 & 65.8 & \multicolumn{2}{|c|}{ (reference) } & \multicolumn{2}{|c|}{ (reference) } \\
\hline Hyperlipidemia & 11,992 & 10,049 & 83.2 & $2.56^{*}$ & $2.41-2.72$ & $1.66^{*}$ & $1.54-1.79$ \\
\hline no Diabetes mellitus & 21,814 & 15,144 & 68.6 & \multicolumn{2}{|c|}{ (reference) } & \multicolumn{2}{|c|}{ (reference) } \\
\hline Diabetes mellitus & 7,003 & 6,179 & 87.8 & $3.28^{*}$ & $3.02-3.56$ & $1.98^{*}$ & $1.79-2.19$ \\
\hline no Myocardial infarction & 26,719 & 19,287 & 71.3 & \multicolumn{2}{|c|}{ (reference) } & \multicolumn{2}{|c|}{ (reference) } \\
\hline Myocardial infarction & 2,098 & 2,036 & 96.9 & $12.66^{*}$ & $9.73-16.47$ & $2.27^{*}$ & $1.60-3.21$ \\
\hline
\end{tabular}

$\mathrm{N}=30,189 ; \% \mathrm{w}=$ weighted percentages; $\mathrm{OR}=$ Odds Ratio estimated by logistic regression; $95 \% \mathrm{Cl}=95 \%$ confidence interval.

\# unadjusted OR;

†adjusted OR from multivariate analyses;

*significant on $5 \%$ level.

OR for increase of 1 year.

doi:10.1371/journal.pone.0052229.t004 
Table 5. Determinants of adequate blood pressure control among physician diagnosed hypertension cases.

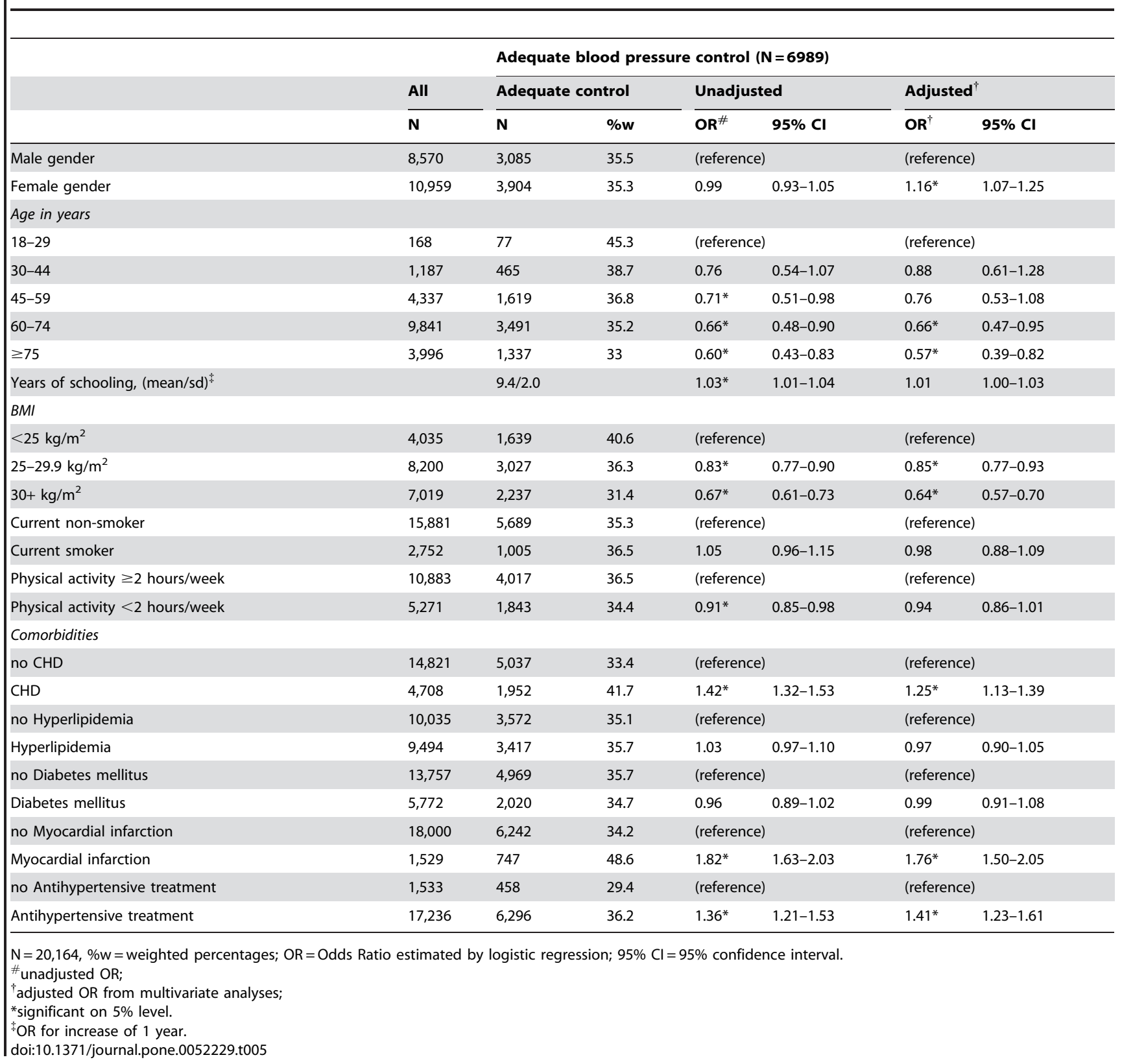

\section{Discussion}

Prevalence of hypertension was dependent on the definition used, and was lowest for $\mathrm{HTN}_{\mathrm{doc}}$ and highest for $\mathrm{HTN}_{\text {NHANES. }}$ Comparison of diagnosis and treatment rates and of the proportion with adequate control among patients in the DETECT and HYDRA studies showed only a small improvement in treatment and control rates between 2001 and 2003 and a slight decline in diagnosis rates. The comorbidities of $\mathrm{CHD}$ and previous myocardial infarction were associated with pharmacotherapy and adequate blood pressure control, whereas for patients with other comorbidities such as DM and hyperlipidemia control was less likely.

\section{Prevalence of Hypertension}

Different definitions of hypertension revealed remarkable differences in prevalence rates. The prevalence rates were lowest for $\mathrm{HTN}_{\text {doc }}$ and $\mathrm{HTN}_{\text {doc,pat }}$ and highest for HTN $\mathrm{HHANES}_{\text {and }}$ $\mathrm{HTN}_{\text {doc,pat,bp }}(56.0 \%$ and $55.2 \%$, respectively). This shows that a considerable fraction of people with hypertension had not been diagnosed by physicians. As a consequence treatment and control rates of $\mathrm{HTN}_{\text {NHANES }}$ based cases are lower in comparison with treatment and control rates based on physician based diagnoses.

Only one study (HYDRA) which is similar to the current one uses the same definitions for hypertension and for the calculation of the prevalence, diagnosis, treatment and control of hypertension [3]. Prevalence rates of hypertension in this study were slightly higher over all groups for $\mathrm{HTN}_{\mathrm{doc}}$ with $38.8 \%$ and slightly lower

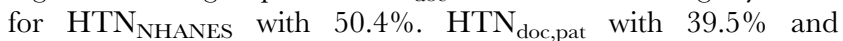
$\mathrm{HTN}_{\text {doc,pat,bp }}$ with $52.4 \%$ were almost in the same range as in the DETECT study. The total prevalence of hypertension based only on physician's assigned diagnosis should be considered with caution and these results were found in both studies. The degree of 
underestimation is more pronounced for the younger patients, but is still notable in the older age groups. Our results for the prevalence rate of hypertension are in accordance with a population-based study for Germany (German National Health Interview and Examination Survey 1998) with prevalence rates only slightly lower if applying NHANES definition criteria in this study $(53.5 \%$ for men and $43.6 \%$ for women) [2]. These results suggest that a substantial proportion of people in primary care with hypertension according to NHANES definition criteria are not diagnosed as hypertensive by physicians in Germany.

In a cohort study with original and offspring cohort members of the Framingham Heart Study, the prevalence rate of hypertension according to the NHANES criteria was $27.3 \%$ in participants younger than 60 years of age, $63.0 \%$ in participants between 60 and 79 years of age and $74.0 \%$ in participants above 80 years of age [24]. These age-specific prevalence rates are lower than for the DETECT study $79.0 \%$ for participants between age $60-74$ and $86.8 \%$ for participants above age 75$)$. One study identified international differences in prevalence, treatment and control rates of hypertension in six different countries (France, Germany, Italy, Spain, UK, US) and used the CardioMonitor Surveys for the year 2004 [25]. In that study, the prevalence of hypertension was determined according to the physician's diagnosis, which is identical to our $\mathrm{HTN}_{\text {doc }}$ definition. Between these six countries there was a range of prevalence rates of hypertension between $78 \%$ in UK and $90 \%$ in Italy, the prevalence in Germany being $86 \%$. The surprisingly high prevalence rates of hypertension in comparison to the DETECT and HYDRA study can be explained partly by the fact, that these surveys were visit-based and not population-based. Physician sampling was based on a quota criterion - each physician had a minimum of 15 patients per week with a cardiovascular disease to be included in the respective countries. Sicker patients were oversampled and as a consequence a selection problem with a high proportion of patients with comorbidities existed. The high prevalence rates for hyperlipidemia with $49 \%$ and for DM with $29 \%$ in the German CardioMonitor survey are in accordance with this interpretation. The prevalence rates in the DETECT study were much lower for hyperlipidemia with $29.5 \%$ and for DM with $12.1 \%$.

\section{Diagnosis, Treatment and Control Rates of Hypertension}

On the one hand, there is a decrease in the proportion of patients diagnosed by physicians in the DETECT study in comparison to the HYDRA study. On the other hand, agespecific treatment and control rates were slightly higher. This means that, despite continuous efforts to improve management of hypertension which have included the publication of the HYDRA results, intense continuous medical education (CME) and intensive training programs, there is only a slight improvement of treatment and control and even a decline in the diagnosis rate.

The WHO-Monica-Augsburg study, conducted in 1994/95, has also reported diagnosis, treatment and control rates which have been in a lower range [4]. In contrast to our study, diagnosis of hypertension was defined as reporting a prior diagnosis of hypertension by the participants instead of using the physicians' diagnosis. Diagnosis rate was about $60 \%$ for women and $50 \%$ for men in 1994/95 and similar to own results in the DETECT study. In comparison with the DETECT study, treatment rates were lower (23\% in men and 33\% in women) and also control rates were lower ( $7 \%$ in men and $13 \%$ in women). Further German studies, for example, the German National Health Interview and Examination Survey in 1998 [16], have the limitation of using another definition for diagnosis of hypertension (awareness) or the study has only been conducted in certain parts of Germany, as the Study of Health in Pomerania (SHIP) [26].

Higher control rates of hypertension were reported in the USA compared to those in Germany [22,27]. In the Framingham Heart Study treatment rates were $68.9 \%$ across the age groups [24]. Overall, the rates of control were $32.4 \%$ in participants with hypertension and $47.0 \%$ in treated participants. The estimated sex-specific rate of control was 38\% for women and $23 \%$ for men.

\section{Factors Associated with Pharmacotherapy}

DETECT also allowed for the evaluation of the impact of patient characteristics as determinants of pharmacotherapy. Patients with higher age and BMI and comorbidities such as CHD, DM, myocardial infarction, hyperlipidemia showed a higher probability of receiving pharmacotherapy, in agreement with guidelines. These results are partially different from those of the ESTHER study, which is a cohort study conducted in a primary care setting in the German Federal State of Saarland [28]. The analyzed sample were hypertensive patients with DM. Similar results for predictors of receiving pharmacotherapy as in the DETECT study were obtained for higher age and BMI, female sex, CHD and current non-smoking. Physical activity and hyperlipidemia had no influence which is in contrast to the DETECT results. A study in the USA of members of the National Health and Human Services Employees Union showed a higher likelihood of receiving pharmacotherapy in participants with a higher age and BMI than in the DETECT and ESTHER study [29]. Sex had, in contrast to the German studies, no influence.

\section{Factors Associated with Blood Pressure Control}

In the DETECT study female sex, a lower BMI, CHD, previous myocardial infarction and antihypertensive medication were associated with adequate blood pressure control. This is in accordance with guideline recommendations that in patients with comorbidities such as CHD or previous myocardial infarction blood pressure control is of high importance. These results are in contrast to the results of the ESTHER study. In this study the only significant negative predictor of an adequate blood pressure in patients with both DM and hypertension was higher age. The difference between DETECT and ESTHER could be explained first by the fact that hypertensive patients with DM are a special subpopulation of hypertensive patients, and second, by choosing a different cut-off point for adequate blood pressure control with a systolic BP of $130 \mathrm{mmHg}$ and a diastolic $\mathrm{BP}$ of $85 \mathrm{mmHg}$ in the ESTHER study.

Results for the prediction of adequate blood pressure control in the DETECT study are also in part in agreement with data for hypertensive patients with DM treated in primary care clinics in the USA [30]. In a retrospective study a higher age was a significant negative predictor for adequate blood pressure control. A history of CHD and also at least one annual visit to a subspecialist had a significant positive influence. In contrast to the results of the DETECT study, no influence of BMI and gender were found and also smoking and physical activity had no influence. Two further studies in the USA estimating control rates had differing results. In the first only female sex and the number of antihypertensive drugs days had a positive significant influence on control of hypertension, whereas higher age, race and a higher BMI played no significant role [29]. The National Health and Nutrition Examination Survey (NHANES) showed that an age of at least 65 years, male sex, not having visited a physician during the last 12 months had a negative predictive value for an adequate blood pressure control in patients aware of their hypertension [31]. Education, family income and current smoking status had no 
influence on blood pressure control. Comparing the results from all these studies with the DETECT study shows that a comorbidity such as CHD leads to a higher probability of adequate control, although other potentially remediable factors such as smoking status or physical activity show no association.

As a first limitation of the DETECT study it should be mentioned that blood pressure measurement was only done once, and not repeatedly, under primary care conditions. For a high degree of certainty about diagnosis of hypertension different methods and using the average of several measurements are recommended [23]. A single measurement could increase the prevalence of hypertension according to the HTN $\mathrm{HHANES}_{\mathrm{N}}$ definition, because the phenomenon of white coat hypertension could subsequently lead to an underestimation of treatment rates and blood pressure control. In the original study which defined the HTN $_{\text {NHANES }}$ criteria for measuring prevalence in the US, two sets of measurements during two different visits had been taken [21]. A second limitation of our analysis is the coding of medical diagnoses DM, CHD and hyperlipidemia: it has been based only on a clinical assessment and has not been validated by objective criteria. A third limitation is that a central laboratory was only used in a subset of patients while in other patients values were taken from the patients records. A fourth limitation is that the time interval between the acquisition of laboratory values and completing the questionnaire was not comparable for all patients, because it was not fixed for all patients. A further limitation was that for estimation of treatment rates of hypertension only pharmacological interventions were considered and no non-pharmacological interventions were taken into account, so that the treatment rates would be higher if non-pharmacological interventions could also have been considered. Estimation of control rates would have been lower if recommended $\mathrm{BP}$ values in the guidelines for patients with comorbidities including hyperlipidemia or DM would have been considered.

\section{References}

1. Hajjar I, Kotchen JM, Kotchen TA (2006) Hypertension: trends in prevalence, incidence, and control. Annu Rev Public Health 27: 465-490.

2. Thamm M (1999) Blood pressure in Germany - current status and trends. Gesundheitswesen 61: S90-93.

3. Sharma AM, Wittchen HU, Kirch W, Pittrow D, Ritz E, et al. (2004) High prevalence and poor control of hypertension in primary care: cross-sectional study. J Hypertens 22: 479-486.

4. Gasse C, Hense HW, Stieber J, Doring A, Liese AD, et al. (2001) Assessing hypertension management in the community: trends of prevalence, detection, treatment, and control of hypertension in the MONICA Project, Augsburg 1984-1995. J Hum Hypertens 15: 27-36.

5. Wolf-Maier K, Cooper RS, Kramer H, Banegas JR, Giampaoli S, et al. (2004) Hypertension treatment and control in five European countries, Canada, and the United States. Hypertension 43: 10-17.

6. National Institute for Health and Clinical Excellence (2008) Prevention of cardiovascular disease at population level. NICE public health guidance 25. London: World Health Organization.

7. World Health Organization (2008) 2008-2013 action plan for the global strategy for the prevention and control of noncommunicable diseases. Geneva: World Health Organization.

8. Pittrow D, Kirch W, Bramlage P, Lehnert H, Hofler M, et al. (2004) Patterns of antihypertensive drug utilization in primary care. Eur J Clin Pharmacol 60: 135142.

9. National Institute for Health and Clinical Excellence (2011) Hypertension: clinical management of primary hypertension in adults, Clinical guidelines, CG127. London.

10. Adler AI, Stratton IM, Neil HA, Yudkin JS, Matthews DR, et al. (2000) Association of systolic blood pressure with macrovascular and microvascular complications of type 2 diabetes (UKPDS 36): prospective observational study. BMJ 321: 412-419.

11. Stamler J, Vaccaro O, Neaton JD, Wentworth D (1993) Diabetes, other risk factors, and 12-yr cardiovascular mortality for men screened in the Multiple Risk Factor Intervention Trial. Diabetes Care 16: 434-444.

12. Mancia G, De Backer G, Dominiczak A, Cifkova R, Fagard R, et al. (2007) 2007 Guidelines for the Management of Arterial Hypertension: The Task Force for the Management of Arterial Hypertension of the European Society of

\section{Conclusions}

Differing definitions of hypertension exist and as a consequence the prevalence rates of hypertension vary accordingly in the DETECT and HYDRA studies. A comparison of the rates of treated and controlled hypertension in the DETECT study with the HYDRA study show indications of small improvements in proportions of patients adequately controlled, although levels of control remain low. With respect to proportions of people diagnosed, there is even a decline. Hypertensive patients with risk factors such as obesity and associated comorbidities such as CHD, hyperlipidemia and DM were more likely to receive antihypertensive drugs in accordance with guidelines. A higher rate of adequate blood pressure control was achieved in patients with obesity and CHD, but not those with DM or hyperlipidemia.

\section{Acknowledgments}

DETECT (Diabetes Cardiovascular Risk-Evaluation: Targets and Essential Data for Commitment of Treatment) is a cross-sectional and prospective-longitudinal, nationwide clinical epidemiological study.

Members of the DETECT-Study group include: Principal investigator: Professor Dr. H.-U. Wittchen; Staff members: Dipl.-Psych. L. Pieper, Dipl.Math. J. Klotsche, Dipl.-Psych. T. Eichler, Dr. H. Glaesmer, E. Katze, Dipl.-Psych. A. Bayer, Dipl.-Psych. A. Neumann. Steering Committee: Professor Dr. H. Lehnert (Lübeck), Professor Dr. G. K. Stalla (Munich), Professor Dr. M. A. M. Zeiher (Frankfurt), Professor Dr. M. Wehling (Mannheim); Advisory Board: Professor Dr. W. März (Graz), Professor Dr. S. Silber (Munich), Professor Dr. Dr. U. Koch (Hamburg), Priv.-Doz. Dr. D. Pittrow (Munich/Dresden).

\section{Author Contributions}

Conceived and designed the experiments: HL GS AZ WM DP SS MW. Performed the experiments: HL GS AZ WM DP SS MW. Analyzed the data: AL JK LP. Contributed reagents/materials/analysis tools: AL JK LP. Wrote the paper: AL JK LP DP FE GS HL SS AZ WM MW HW.

Hypertension (ESH) and of the European Society of Cardiology (ESG). J Hypertens 25: 1105-1187.

13. Turnbull F, Neal B, Algert C, Chalmers J, Chapman N, et al. (2005) Effects of different blood pressure-lowering regimens on major cardiovascular events in individuals with and without diabetes mellitus: results of prospectively designed overviews of randomized trials. Arch Intern Med 165: 1410-1419.

14. Zanchetti A, Grassi G, Mancia G (2009) When should antihypertensive drug treatment be initiated and to what levels should systolic blood pressure be lowered? A critical reappraisal. J Hypertens 27: 923-934.

15. Hackam DG, Khan NA, Hemmelgarn BR, Rabkin SW, Touyz RM, et al. (2010) The 2010 Canadian Hypertension Education Program recommendations for the management of hypertension: part 2 - therapy. Can J Cardiol 26: 249258.

16. Janhsen K, Strube H, Starker A (2008) Hypertonie. Berlin: Robert-KochInstitut.

17. Pieper L, Wittchen HU, Glaesmer H, Klotsche J, Marz W, et al. (2005) Cardiovascular high-risk constellations in primary care. DETECT Study 2003. Bundesgesundheitsblatt Gesundheitsforschung Gesundheitsschutz 48: 1374 1382.

18. Wittchen HU, Glaesmer H, Marz W, Stalla G, Lehnert H, et al. (2005) Cardiovascular risk factors in primary care: methods and baseline prevalence rates-the DETECT program. Curr Med Res Opin 21: 619-630.

19. Wittchen HU, Krause P, Hofler M, Pfister H, Kupper B, et al. (2003) Aim, design and methods of the "Hypertension and diabetes screening and awareness" - (HYDRA) study. Fortschr Med Orig 121 Suppl 1: 2-11.

20. Chobanian AV, Bakris GL, Black HR, Cushman WC, Green LA, et al. (2003) The Seventh Report of the Joint National Committee on Prevention, Detection, Evaluation, and Treatment of High Blood Pressure: the JNC 7 report. JAMA 289: 2560-2572.

21. Burt VL, Whelton P, Roccella EJ, Brown C, Cutler JA, et al. (1995) Prevalence of hypertension in the US adult population. Results from the Third National Health and Nutrition Examination Survey, 1988-1991. Hypertension 25: 305313.

22. Burt VL, Cutler JA, Higgins M, Horan MJ, Labarthe D, et al. (1995) Trends in the prevalence, awareness, treatment, and control of hypertension in the adult 
US population. Data from the health examination surveys, 1960 to 1991. Hypertension 26: 60-69.

23. Powers BJ, Olsen MK, Smith VA, Woolson RF, Bosworth HB, et al. (2011) Measuring blood pressure for decision making and quality reporting: where and how many measures? Ann Intern Med 154: 781-788, W-289-790.

24. Lloyd-Jones DM, Evans JC, Levy D (2005) Hypertension in adults across the age spectrum: current outcomes and control in the community. JAMA 294: 466472.

25. Wang YR, Alexander GC, Stafford RS (2007) Outpatient hypertension treatment, treatment intensification, and control in Western Europe and the United States. Arch Intern Med 167: 141-147.

26. Meisinger C, Heier M, Volzke H, Lowel H, Mitusch R, et al. (2006) Regional disparities of hypertension prevalence and management within Germany. J Hypertens 24: 293-299.
27. Wolf-Maier K, Cooper RS, Banegas JR, Giampaoli S, Hense HW, et al. (2003) Hypertension prevalence and blood pressure levels in 6 European countries, Canada, and the United States. JAMA 289: 2363-2369.

28. Raum E, Lietzau S, Stegmaier C, Brenner H, Rothenbacher D (2008) For the majority of patients with diabetes blood pressure and lipid management is not in line with recommendations. Results from a large population-based cohort in Germany. Pharmacoepidemiol Drug Saf 17: 485-494.

29. Stockwell DH, Madhavan S, Cohen H, Gibson G, Alderman MH (1994) The determinants of hypertension awareness, treatment, and control in an insured population. Am J Public Health 84: 1768-1774.

30. Duggirala MK, Cuddihy RM, Cuddihy MT, Naessens JM, Cha SS, et al. (2005) Predictors of blood pressure control in patients with diabetes and hypertension seen in primary care clinics. Am J Hypertens 18: 833-838.

31. Hyman DJ, Pavlik VN (2001) Characteristics of patients with uncontrolled hypertension in the United States. N Engl J Med 345: 479-486. 